\title{
Overview of processing technologies for tungsten-steel composites and FGMs for fusion applications
}

Jiří Matějíček, Barbara Nevrlá, Monika Vilémová, Hanna Boldyryeva

\begin{abstract}
Tungsten is a prime candidate material for the plasma-facing components in future fusion devices, e.g. ITER and DEMO. Because of the harsh and complex loading conditions and the differences in material properties, joining of the tungsten armor to the underlying construction and/or cooling parts is a complicated issue. To alleviate the thermal stresses at the joint, a sharp interface may be replaced by a gradual one with a smoothly varying composition. In this paper, several techniques for the formation of tungsten-steel composites and graded layers are reviewed. These include plasma spraying, laser cladding, hot pressing and spark plasma sintering. Structure, composition and selected thermal and mechanical properties of representative layers produced by each of these techniques are presented. A summary of advantages and disadvantages of the techniques and an assessment of their suitability for the production of plasma-facing components is provided.
\end{abstract}

Key words: plasma-facing components $\bullet$ functionally graded materials (FGMs) • tungsten • steel • plasma spraying $\bullet$ powder metallurgy

J. Matějíček ${ }^{\bowtie}$ B. Nevrlá, M. Vilémová, H. Boldyryeva Institute of Plasma Physics ASCR,

Za Slovankou 3, 18200 Prague 8, Czech Republic, Tel.: +420 26605 3307, Fax: +420 286586389 ,

E-mail: jmatejic@ipp.cas.cz

Received: 9 June 2014

Accepted: 19 November 2014

\section{Introduction}

Materials to be used in future fusion reactors will be subject to complex loading in a very harsh environment. In particular, the plasma-facing components (PFCs) will be subject to extremely high heat and particle fluxes from the hot plasma, both in the form of a steady state loading and transient events. Since no single material can fulfill the demands of a complete component in such conditions, combinations of materials have to be used. A prime candidate for the plasma-facing surface (armor) is tungsten, thanks to its high resistance to sputtering, high melting point, good thermal conductivity, etc. [1, 2]. Among its disadvantages are the brittle nature and the fact that it is difficult to process and machine. The armor has to be joined to the underlying parts, made either of copper (in ITER) or steel (in DEMO), which provide the necessary mechanical support and active cooling. The joining of dissimilar materials presents a number of challenges, chief of them being the development of stresses at the interface upon thermal loading. These stresses can be effectively reduced by introduction of the so-called functionally graded materials (FGMs) which replace the sharp interface with a gradual transition in composition $[3,4]$. Further issues to be considered in joining include possible reaction of the materials, changes 


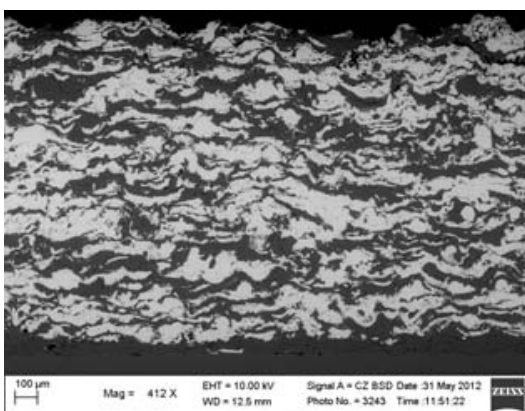
a)

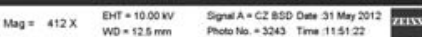

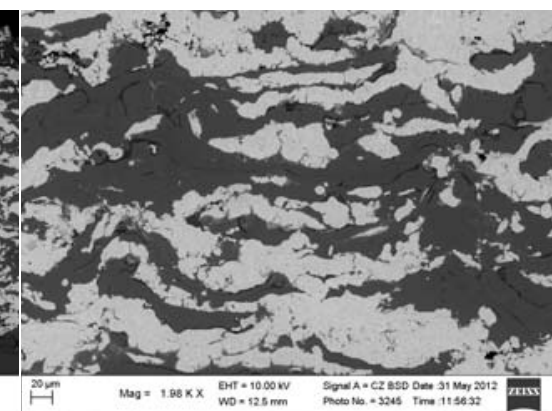

b)

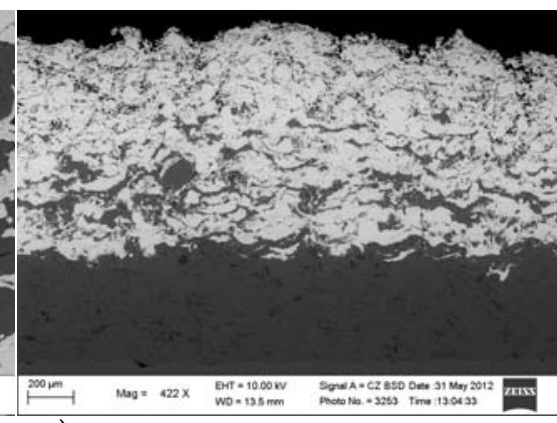

c) in properties due to elevated processing temperature, feasible size and shape of the parts, etc.

In this paper, several techniques for the preparation of tungsten-steel composites and FGMs, which can serve either as bonding interlayers or provide the full substrate+armor compound, are presented. These are namely plasma spraying, laser cladding, hot pressing and spark plasma sintering. For each technique, the principle is first briefly reviewed. Then, examples of the microstructures obtained in our experiments and selected thermal and/or mechanical properties are given. Finally, the relative advantages and drawbacks of each technique are summarized and their suitability for the fabrication of PFCs is assessed.

\section{Plasma spraying}

In plasma spraying (PS), the material to be deposited is introduced as a powder (typically tens of $\mu \mathrm{m}$ in size) into the plasma jet (typically 10000 to $20000 \mathrm{~K}$ hot) which melts and propels the particles towards the substrate, where they flatten, cool down and solidify rapidly, thus forming a solid coating. Plasma sprayed coatings possess a specific lamellar structure consisting of the flattened droplets (called 'splats'), microscopic (often elongated) pores, occasional cracks and regions of imperfect bonding between the splats. This gives them unique properties, namely anisotropy, lower thermal conductivity and specific mechanical properties (e.g. lower Young's modulus and strength, but higher strain tolerance) $[5,6]$. The compositional profile of the coating can be easily controlled by adjusting the amount of different powders fed to the plasma jet through separate injectors.
Representative microstructures of the tungsten-steel composites and FGMs prepared by water/ argon stabilized plasma spraying [7] are shown in Fig. 1. Figure 1a gives an overview of a uniform 50/50 composite. A homogeneous mixing of the two phases can be seen. Contrary to the atomic level deposition techniques, such as PVD, the plasma-sprayed composites/FGMs are composed of splats, i.e. discrete particles whose dimensions are determined by the original size of the powder particles. Figure $1 \mathrm{~b}$ shows the microstructure in a greater detail, with some areas of imperfect bonding between the splats, as well as oxide layers on the steel splats. In contrast to the powder metallurgy techniques discussed below, there is no mutual reaction between the tungsten and steel phases in this case. In Fig. 1c a full stepwise FGM is shown, composed of five layers spanning the range from pure steel to pure tungsten. Typical properties of selected coatings prepared by water stabilized (WSP) and water/argon stabilized (WSP-H) plasma spraying are listed in Table 1.

The main advantage of plasma spraying from the point of view of prospective application on PFCs is its ability to cover large areas, including non-planar surfaces, with a coating of significant thickness (up to several $\mathrm{mm}$ ) [8]. The thin film deposition techniques, like PVD or CVD, typically stay in the $\mu \mathrm{m}$ range; this is comparable to the thickness of the material that gets eroded within one disruption [9]. Among various plasma-spraying systems, WSP features much higher material throughput than the more common gas stabilized torches, as well as higher plasma temperature, favorable for melting refractory materials. Another important aspect of this and other coating techniques is that the FGM

Table 1. Typical properties ( $\lambda=$ thermal conductivity, $\mathrm{E}=$ Young's modulus $)$ of tungsten, steel and tungsten-steel composites (of nominally 50/50 vol\% composition or the closest available), prepared by different techniques. Some properties were not determined for all the samples. The presented values were determined in our experiments with specific processing parameters; different values could be obtained in different settings/variations of the listed techniques

\begin{tabular}{lccccc}
\hline \multicolumn{1}{c}{ Property } & WSP & WSP-H & LC & HP & SPS \\
\hline$\lambda-100 \% \mathrm{~W}[\mathrm{~W} / \mathrm{m} . \mathrm{K}]$ & 16 & 11 & 28 & 168 & 153 \\
$\lambda-50 / 50[\mathrm{~W} / \mathrm{m} . \mathrm{K}]$ & 15 & 15 & 32 & 30 & 49 \\
$\lambda-100 \%$ steel $[\mathrm{W} / \mathrm{m} . \mathrm{K}]$ & 11 & 9 & & 25 & 26 \\
$\mathrm{E}-100 \% \mathrm{~W}[\mathrm{GPa}]$ & 74 & 57 & & 400 & \\
$\mathrm{E}-50 / 50[\mathrm{GPa}]$ & 57 & 60 & & 230 & \\
E- $100 \%$ steel $[\mathrm{GPa}]$ & 45 & 62 & 12 & 13 & 14 \\
Reference & 10 & 7,11 & & & \\
\hline
\end{tabular}


together with the pure $\mathrm{W}$ surface can be laid directly on the cooling/structural components; therefore, no further joining is necessary. As seen in Fig. 1b, there is no intermetallic formation, despite the fact that both phases get into contact in molten state, i.e. at higher temperatures than in spark plasma sintering (SPS) (see below). The rapid solidification, together with imperfect contact, is likely responsible for the lack of interdiffusion across the interfaces. The presence of the oxide is, of course, undesirable - besides oxygen being an unwanted impurity in a fusion device, it also contributes to the reduction of the thermal conductivity of the layers. The oxidation is inevitable when spraying in an ambient atmosphere and takes place in two stages: first, when the molten particles travel through a mixture of the plasma and the air, and second, after their impact, when they are exposed to the air at only moderately elevated temperature, but for a longer time. Various means of shrouding were only partially successful in suppressing the oxidation during atmospheric spraying [15]. It can be eliminated by spraying in vacuum; however, such systems are not widely available and can only be used together with low power torches, which, in turn, may have difficulty properly melting the refractory tungsten. A separate feeding of powders enables easy control of the compositional profile by adjusting the individual feed rates [10]. The example shown above consists of five distinct layers, each made in several torch passes; however, the feed rates can be adjusted for each torch pass. Different deposition efficiencies of the two materials also have to be taken into account. As in other applications, plasma spraying can be also used to repair worn/eroded parts.

A major drawback of this technique, is the low thermal conductivity [6], stemming from the porous and lamellar structure of the coatings. This has the effect that upon thermal loading from the plasma, the heat is more concentrated in the surface region - as compared to more conductive materials - which is then susceptible to a more severe damage. A characteristic damage mode in high heat flux tests [16] was surface melting and partial delamination in near-surface region. When a similar loading was applied to bulk tungsten, melting did not occur, thanks to efficient heat transfer, but cracks perpendicular to the surface frequently occurred, reaching much deeper into the material. Several methods of post-treatment to increase the conductivity were explored, such as molten copper infiltration, laser surface re-melting and densification by hot isostatic pressing $[17,18]$. While successful in reducing the porosity and increasing the thermal conductivity, their application often weakens some of the advantages of the plasma spraying technique mentioned above. Given these limitations, plasma-sprayed coatings may be applicable only to regions subject to moderate heat fluxes.

\section{Laser cladding}

In laser cladding (LC), sometimes called laser spraying, the powder to be deposited is introduced into a laser beam, close to its focal point, while the beam traverses across the substrate. The powder particles - either molten, semi-molten or solid - get incorporated into a melt pool created on the substrate by the heat input from the laser [19]. The composite is consolidated when the beam moves away from the melted region.

Figure 2a shows a uniform mixed layer formed by two passes of the laser. A homogeneous mixing of the spherical tungsten particles in the steel melt pool can be seen, and no distinct boundary between the two passes can be found. In Fig. 2b, a double layer consisting of a mixed layer on the steel substrate and a pure $\mathrm{W}$ layer on the top is shown. While the tungsten layer is dense, indicating good tungsten melting, large pores are visible underneath it, probably as a result of steel phase evaporation. In other laser settings a good contact between the top W layer and the mixed layer was achieved, however, with small porosity throughout the $\mathrm{W}$ layer. Figure 2c shows a double layer made by two passes with different size W powders $(<50 \mu \mathrm{m}$ and $50-90 \mu \mathrm{m})$. This resulted in a different composition - the $\mathrm{W} / \mathrm{Fe}$ ratio was $\sim 1.5$ and $\sim 11$, respectively.

Laser cladding is a compact and flexible technology that shares several advantages with plasma spraying. As a coating technology it also does not need any further joining, it is suitable for covering large areas (albeit at a slower deposition rate) and is even more flexible in coating curved surfaces and repairing damaged parts. Since the heating/ melting occurs very locally, it features minimal heat input to the coated part. Fully dense composites and graded layers can be formed. Although the formation of a fully dense top layer of tungsten was not achieved in these limited experiments, its melting and consolidation was demonstrated, and an im-

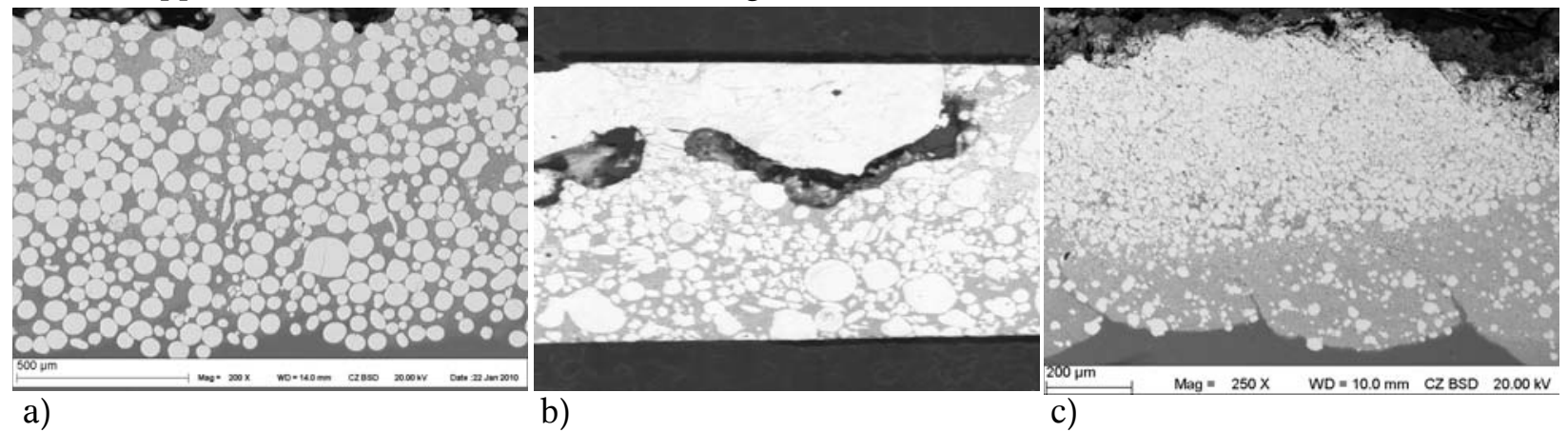

Fig. 2. Laser-clad layers: a) a uniform W-Fe layer; b) a double layer of W-Fe mixture and pure W; c) a double layer of $\mathrm{W}$-Fe mixtures with different $\mathrm{W} / \mathrm{Fe}$ ratio. 
a)

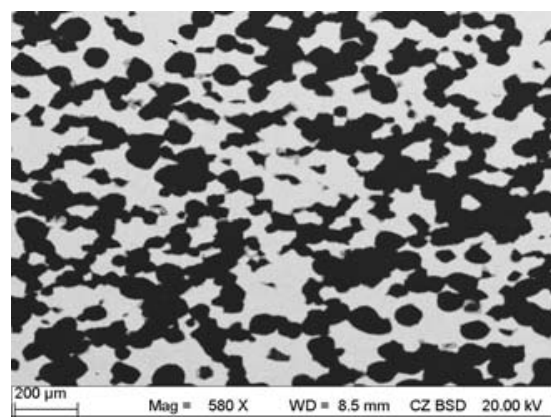

b)

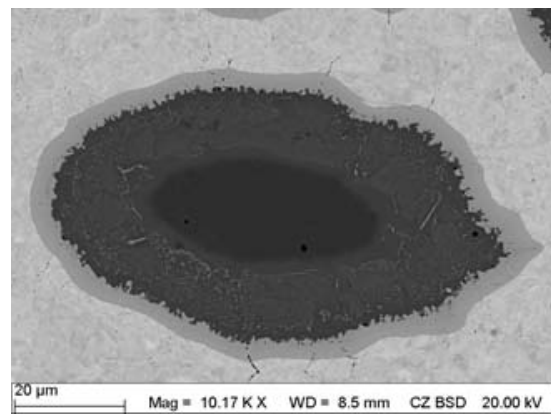

c)

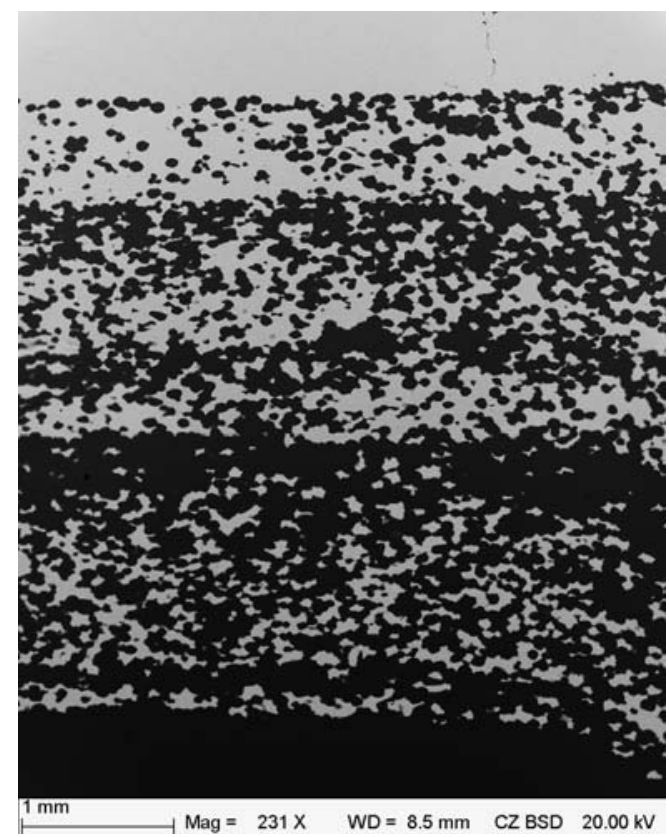

Fig. 3. Hot-pressed layers: a) a uniform 50/50 composite; b) a detailed view of a steel grain surrounded by the tungsten (in a $75 \% \mathrm{~W}$ composite); c) a full FGM.

provement of the technology with proper optimization of the process parameters can be expected.

\section{Hot pressing}

Hot pressing (HP) is a technique belonging to the family of powder metallurgy processes. A powder or a mixture of powders is placed in an externally heated graphite die and uniaxially compressed. The powder is consolidated by sintering and creep processes as a result of simultaneous heating and application of pressure.

Figure 3 shows examples of tungsten-steel structures obtained by hot pressing at $2000^{\circ} \mathrm{C}$ and $6 \mathrm{GPa}$ [13]. Figure 3a presents a 50/50 composite, showing a uniform mixing of the two powders of similar size and a fully dense compact. The individual grains have an ellipsoidal shape (with roughly equiaxial particles of the starting powders) as a result of the uniaxial pressure. In Fig. 3b, a detailed image of a steel grain surrounded by tungsten is shown. A noticeable metallurgical reaction can be seen, resulting in the formation of $\sim 3 \mathrm{~mm}$ thick intermetallic layer at the tungsten-steel interface, and a micro-composite consisting of this intermetallic and steel at the steel side of the interface. The intermetallic layer was identified as $\mathrm{Fe}_{2} \mathrm{~W}$ by the X-ray diffraction on the cross section, although traces of $\mathrm{Fe}_{7} \mathrm{~W}_{6}$ were also detected on the surface previously in contact with the die. Nanoindentation measurements of the individual phases revealed an increased hardness, an intermediate value of Young's modulus and a lower ratio of plastic to elastic work, as compared to the tungsten and steel phases [13]. Apart from the intermetallic layer formation, significant interdiffusion of the $\mathrm{W}$ and Fe species as well as carbon from the die-stimulated by the elevated temperature - was observed by energy-dispersive spectrometry. Figure $3 c$ shows the struc- ture of a full FGM, composed of five layers of distinct composition. The boundaries of these layers can be easily discerned and a slight deviation of planarity can be seen. This is a consequence of manual pouring of the powders into the die, and was eliminated by introducing thin steel foils between the layers, which consolidated well with the powders upon sintering. As expected, the properties of the hot-pressed pure materials were similar to those tabulated for bulk materials, and the composites roughly followed the rule of mixtures.

As shown above, this technique is capable of producing fully dense composites and FGMs, which is important for the thermal conductivity and consequently for the ability to withstand high heat fluxes. The high temperature consolidation (though it can be performed at somewhat lower temperature than in the current example) leads to interdiffusion of $\mathrm{W}$ and $\mathrm{Fe}$ and the formation of W-Fe intermetallic. The presence of a brittle phase, albeit in a small fraction, can undermine the structural integrity of the composite loaded by thermal cycling or thermal shocks. However, the exact role of this intermetallic layer still needs to be properly investigated. As with other powder metallurgy techniques, the size of compounds produced this way is limited to few $\mathrm{cm}^{2}$, although larger scale industrial facilities exist. In considering the prospective application for a tokamak-type fusion device, the difficulty in covering several hundred $\mathrm{m}^{2}$ of plasma-facing surface would have to be balanced with the ability to provide fully dense and highly conductive layers.

\section{Spark plasma sintering}

Spark plasma sintering (SPS), sometimes also called field assisted sintering technique (FAST), is a specific variant of sintering technology that uses electrical 


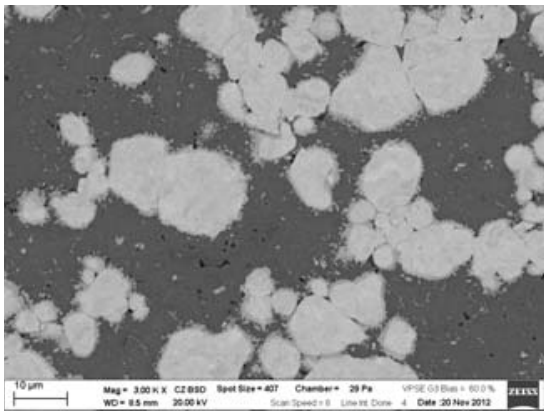

a)

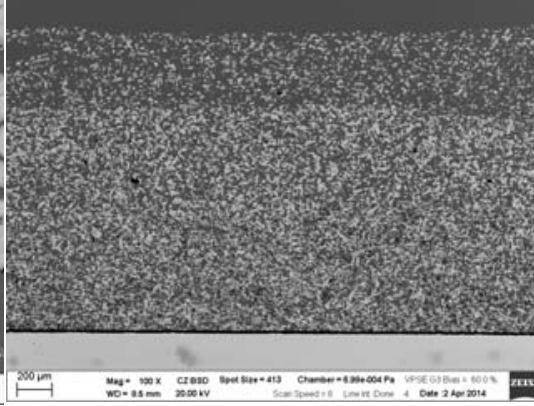

b)

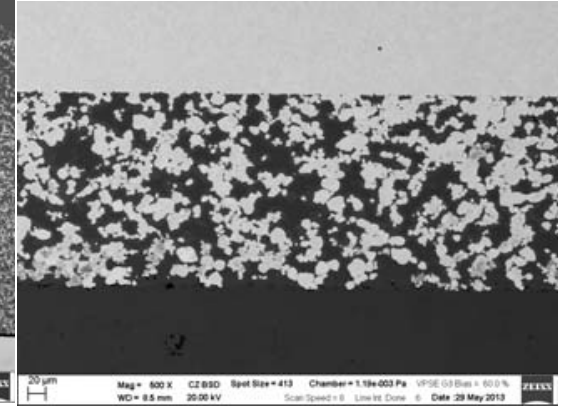

c)

Fig. 4. SPS layers: a) a detailed view of a uniform 50/50 composite; b) a full FGM; c) a bulk tungsten and steel bonded with a mixed powder interlayer.

current besides the temperature and the pressure. In this technology, either a steady or pulsed current passes through both the die and the powder (when conductive powder is used) or only through the die (for non-conductive powders), and the whole assembly is heated resistively (Joule heating). This mode allows much faster heating rates and therefore shorter processing times. Besides saving energy, this also limits grain growth in the material and helps to preserve favorable properties of fine grained materials. Additionally, in conductive powders the Joule heating is concentrated at the points of contact and accelerates sintering. Thus, the same results can be achieved at lower temperatures than with conventional sintering techniques.

Figure 4 a shows a representative microstructure of a $50 / 50$ composite sintered by SPS at $1100^{\circ} \mathrm{C}$. A fully dense structure can be seen, with a thin $(\sim 1 \mu \mathrm{m})$ intermetallic interlayer between tungsten and steel. Contrary to the hot pressing case, this was identified as $\mathrm{Fe}_{7} \mathrm{~W}_{6}$, i.e. the higher temperature intermetallic. At $1300^{\circ} \mathrm{C}$, this interlayer was $\sim 5 \mu \mathrm{m}$ thick. Despite much lower processing temperature, the thickness was in the same range as in hot pressing. Apparently, the applied electrical current enhances the interdiffusion across the interface. In Fig. $4 b$, a stepwise layered FGM is shown. To ensure proper bonding at the $\mathrm{W}$-rich end, pure tungsten was sintered first $\left(1600^{\circ} \mathrm{C}\right)$ and then the remaining layers from $75 \%$ $\mathrm{W}$ to $100 \%$ steel were added and sintered $\left(1000^{\circ} \mathrm{C}\right)$. Figure $4 \mathrm{c}$ demonstrates the capability of this technique to bond bulk materials - bulk steel and tungsten layers were bonded together with a thin interlayer of $50 / 50$ powder at $1100^{\circ} \mathrm{C}$. A sound bonding on both faces, without gaps or pores, can be seen.

The advantages and drawbacks of SPS are rather similar to hot pressing; the main difference being a lower processing temperature and a shorter time. Experiments with single powders of different particle size showed that powders with smaller particles require lower temperatures to achieve a full density compact, for example, a $<20 \mu \mathrm{m} \mathrm{W}$ powder was fully sintered at $2100^{\circ} \mathrm{C}$, while the $0.7 \mu \mathrm{m}$ one at $1600^{\circ} \mathrm{C}$. In powder mixtures, intermetallic formation was observed at or above $\sim 1000^{\circ} \mathrm{C}$. In the investigations reported here no process window was found for the full FGMs that would ensure full sintering at the tungsten side and at the same time avoid the intermetallic formation. A compromise approach could consist of a two-step sintering, i.e. pure tungsten at higher temperature and $\mathrm{W}+$ steel mixtures and steel at a lower one. Investigations into other possible ways to avoid the intermetallic formation and to determine how critical is its presence for the FGM performance are under way.

\section{Other techniques}

There are several other techniques applicable for FGM formation and/or joining of tungsten and steel for PFCs. Physical vapor deposition (PVD) is a deposition technique able to produce completely smooth FGMs (down to the atomic level). Typical thicknesses are in the range of $\mu \mathrm{m}$, which would not provide sufficient lifetime as the plasma facing surface, but the coatings may be used as bonding interlayers [4]. Apart from those mentioned above, other variants of powder metallurgy techniques are also applicable. Resistance sintering under ultra-high pressure (RSUHP) uses both an electrical current passing through the powder and a very high pressure that helps overcome the large difference in melting of tungsten and steel [20]. Isostatic pressing, taking place in two steps - pressing the powders at very high pressure in a flexible mold and then heat-treating the compact to finish the sintering enables near-net shape fabrication of more complex geometries. Hot isostatic pressing, using gas as the pressurizing medium, overcomes some of the limitations of solid dies/punches [17]. Several FGM fabrication techniques were reviewed in [21]. The tungsten-steel bonding can be achieved by a number of techniques, including those using a third material as a bonding interlayer, instead of an FGM $[22,23]$.

\section{Conclusions}

In this article, four different techniques for the preparation of tungsten-steel composites and FGMs were presented and compared. Representative structures and selected properties were shown, and the particular techniques were discussed with regards to their applicability for fabrication of PFCs in future fusion devices. These aspects are concisely summarized in Table 2. Considering their advantages and drawbacks, there is no clear 'winner' that would be 
Table 2. A comparison of application-relevant features of the four techniques

\begin{tabular}{lcccc}
\hline & PS & LC & HP & SPS \\
\hline Area coverage & large & moderate & small & small \\
Material throughput & large & moderate & small & small \\
Heat input to substrate & low & very low & very high & high \\
Possibility of repairs & yes & yes & unlikely & unlikely \\
Conductivity & low & moderate/high & high & high \\
Density & $95-98 \%$ & nearly full & full & full \\
Intermetallic formation & no & no & yes & yes \\
Need of further bonding & no & no & yes & yes \\
\hline
\end{tabular}

favorable in all or majority of the aspects. Further research is needed that would include performance testing at reference conditions, and various aspects (including those not discussed here) have to be integrated with specific weight into a global assessment. It is possible that different techniques might be used at different locations.

Acknowledgment. Support from the Czech Science Foundation through grant no. P108/12/1872 is acknowledged.

\section{References}

1. Pintsuk, G. (2012). Tungsten as a plasma-facing material. In R. J. M. Konings (Ed.), Comprehensive nuclear materials (pp. 551-581). Elsevier.

2. Rieth, M., Dudarev, S. L., Gonzalez De Vicente, S. M., Aktaa, J., Ahlgren, T., Antusch, S., Armstrong, D. E. J., Balden, M., Baluc, N., Barthe, M. -F., Basuki, W. W., Battabyal, M., Becquart, C. S., Blagoeva, D., Boldyryeva, H., Brinkmann, J., Celino, M., Ciupinski, L., Correia, J. B., De Backer, A., Domain, C., Gaganidze, E., García-Rosales, C., Gibson, J., Gilbert, M. R., Giusepponi, S., Gludovatz, B., Greuner, H., Heinola, K., Höschen, T., Hoffmann, A., Holstein, N., Koch, F., Krauss, W., Li, H., Lindig, S., Linke, J., Linsmeier, Ch., López-Ruiz, P., Maier, H., Matějíček, J., Mishra, T. P., Muhammed, M., Muñoz, A., Muzyk, M., Nordlund, K., Nguyen-Manh, D., Opschoor, J., Ordás, N., Palacios, T., Pintsuk, G., Pippan, R., Reiser, J., Riesch, J., Roberts, S. G., Romaner, L., Rosinski, M., Sanchez, M., Schulmeyer, W., Traxler, H., Ureña, A., van der Laan, J. G., Veleva, L., Wahlberg, S., Walter, M., Weber, T., Weitkamp, T., Wurster, S., Yar, M. A., You, J. H., \& Zivelonghi, A. (2013). Recent progress in research on tungsten materials for nuclear fusion applications in Europe. J. Nucl. Mater., 432(1/3), 482-500. DOI: 10.1016/j.jnucmat.2013.03.062.

3. Missiaen, J. M., Raharijaona, J. J., Antoni, A., Pascal, C., Richou, M., \& Magaud, P. (2011). Design of a $\mathrm{W} / \mathrm{steel}$ functionally graded material for plasma facing components of DEMO. J. Nucl. Mater., 416(3), 262-269. DOI: 10.1016/j.jnucmat.2011.05.054.

4. Weber, T., Stueber, M., Ulrich, S., Vaßen, R., Basuki, W. W., Lohmiller, J., Sittel, W., \& Aktaa, J. (2013). Functionally graded vacuum plasma sprayed and magnetron sputtered tungsten/Eurofer97 interlayers for joints in helium-cooled divertor components. J. Nucl. Mater., 436(1/3), 29-39. DOI: 10.1016/j. jnucmat.2013.01.286.

5. Mušálek, R., Matějíček, J., Vilémová, M., \& Kovářik, O. (2010). Non-linear mechanical behavior of plasma sprayed alumina under mechanical and thermal loading. J. Therm. Spray Technol., 19(1/2), 422-428. DOI: 10.1007/s11666-009-9362-x.

6. Vilémová, M., Matějíček, J., Mušálek, R., \& Nohava, J. (2012). Application of structure-based models of mechanical and thermal properties on plasma sprayed coatings. J. Therm. Spray Technol., 21 (3/4), 372-382. DOI: 10.1007/s11666-012-9739-0.

7. Matějíček, J., Vilémová, M., Kavka, T., Ctibor, P., Mušálek, R., Medřický, J., \& Iždinský, K. (2015). Tungsten-steel composites and FGMs prepared by hybrid water-argon plasma spraying. To appear in Surface and Coatings Technology.

8. Matějíček, J., Chráska, P., \& Linke, J. (2007). Thermal spray coatings for fusion applications - review. J. Therm. Spray Technol., 16(1), 64-83. DOI: 10.1007/ s11666-006-9007-2.

9. Hassanein, A., \& Konkashbaev, I. (1996). Lifetime evaluation of plasma-facing materials during a tokamak disruption. J. Nucl. Mater., 233, 713-717. DOI: 10.1016/S0022-3115(96)00213-9.

10. Matějíček, J., \& Boldyryeva, H. (2009). Processing and temperature-dependent properties of plasma-sprayed tungsten-stainless steel composites. Phys. Scripta, T138, 014041. DOI: 10.1088/00318949/2009/T138/014041.

11. Vilémová, M., Nevrlá, B., \& Matějíček, J. (2012). Mechanical and thermal properties of tungsten composite coatings. In Coatings and layers (pp. 135-140). Trenčín: LISS.

12. Matějíček, J., Boldyryeva, H., \& Ambrož, P. (2015). Tungsten-steel composites and FGMs prepared by laser cladding. To appear in Fusion Science and Technology.

13. Matějíček, J., Boldyryeva, H., Brožek, V., Čižmárová, E., \& Pala, Z. (2012). Tungsten-steel composites and FGMs produced by hot pressing. In: 21st International Conference on Metallurgy and Materials METAL 2012 (paper no. 177). Ostrava, Tanger.

14. Matějíček, J., Dlabáček, Z., Nevrlá, B., Vilémová, M., Dlabáček, Z., Pala, Z., Čech, J., Klevarová, V., Kocmanová, L., Haušild, P., \& Cinert, J. (2015). Processing and properties of tungsten-steel composites and FGMs prepared by spark plasma sintering. To appear in Fusion Engineering and Design.

15. Matějíček, J., Kavka, T., Bertolissi, G., Ctibor, P., Vilémová, M., Mušálek, R., \& Nevrlá, B. (2013). The role of spraying parameters and inert gas shrouding in hybrid water-argon plasma spraying of tungsten and copper for nuclear fusion applications. J. Therm. Spray Technol., 22(5), 744-755. DOI: 10.1007/ s11666-013-9895-x.

16. Matějíček, J., Koza, Y., \& Weinzettl, V. (2005). Plasma sprayed tungsten-based coatings and their performance under fusion relevant conditions. Fusion Eng. Des., 75(9), 395-399. DOI: 10.1016/j. fusengdes.2005.06.006. 
17. Matějíček, J., Iždinský, K., \& Vondrouš, P. (2009). Methods of increasing thermal conductivity of plasma sprayed tungsten-based coatings. Adv. Mater. Res., $59,82-86$

18. Matějíček, J., \& Holub, P. (2014). Laser remelting of plasma-sprayed tungsten coatings. J. Therm. Spray Technol., 23(4), 750-754. DOI: 10.1007/s11666014-0067-4.

19. Laser cladding. Retrieved May 27, 2014 from http://en.wikipedia.org/wiki/Cladding_ (metalworking)\#Laser_cladding.

20. Weber, T., Zhou, Z., Qu, D., \& Aktaa, J. (2011). Resistance sintering under ultra high pressure of tungsten/ Eurofer97 composites. J. Nucl. Mater., 414(1), 19-22. DOI: 10.1016/j.jnucmat.2011.04.024.
21. Weber, T., \& Aktaa, J. (2011). Numerical assessment of functionally graded tungsten/steel joints for divertor applications. Fusion Eng. Des., 86(2/3), 220-226. DOI: 10.1016/j.fusengdes.2010.12.084.

22. Aktaa, J., Basuki, W. W., Weber, T., Norajitra, P., Krauss, W., \& Konys, J. (2014). Manufacturing and joining technologies for helium cooled divertors. Fusion Eng. Des., 89(7/8), 913-920. DOI: 10.1016/j. fusengdes.2014.01.028.

23. Matějíček, J., Vilémová, M., Mušálek, R., Sachr, P., \& Horník, J. (2013). The influence of interface characteristics on the adhesion/cohesion of plasma sprayed tungsten coatings. Coatings, 3(2), 108-125. DOI: 10.3390/coatings3020108. 